\title{
The new WHO classification of gastrointestinal neuroendocrine tumors and immunohistochemical expression of somatostatin receptor 2 and 5
}

\author{
OANA POPA ${ }^{1,2^{*}}$, SORINA MARIA TABAN ${ }^{1 *}$, STELIAN PANTEA $^{3}$, \\ ANDREI DOREL PLOPEANU ${ }^{1,4}$, ROBERT ALEXANDRU BARNA ${ }^{1,5}$, MARIOARA CORNIANU $^{1}$, \\ ANCA-ARIANA PASCU ${ }^{5}$ and ALIS LILIANA CARMEN DEMA ${ }^{1 *}$
}

\begin{abstract}
${ }^{1}$ Department of Microscopic Morphology-Pathology, ANAPATMOL Research Center, 'Victor Babeș' University of Medicine and Pharmacy of Timisoara, 300041 Timisoara; ${ }^{2}$ Endocrinology Clinic, 'Pius Brînzeu' County Emergency Clinical Hospital, 300723 Timisoara; ${ }^{3}$ Surgical Emergency Clinic, 'Victor Babeș' University of Medicine and Pharmacy of Timisoara, 300041 Timisoara; ${ }^{4}$ Anatomic Pathology Service, 'Pius Brînzeu' County Emergency Clinical Hospital, 300723 Timisoara;

${ }^{5}$ Department of Internal Medicine II-Discipline of Gastroenterology and Hepatology,

'Victor Babeș' University of Medicine and Pharmacy of Timisoara, 300041 Timisoara, Romania
\end{abstract}

Received June 2, 2021; Accepted July 2, 2021

DOI: $10.3892 / \mathrm{etm} .2021 .10613$

\begin{abstract}
The 2019 World Health Organization (WHO) classification of gastrointestinal tumors defines well-differentiated grade 3 neuroendocrine tumors, the mixed neuroendocrine-non-neuroendocrine tumors (MiNENs) and classifies goblet cell carcinoid as goblet cell adenocarcinoma. The expression of somatostatin receptors (SSTRs) is the foundation for somatostatin analogue therapy. At present, there are only a few studies that have analyzed the immunohistochemical reactivity of SSTRs in gastrointestinal neuroendocrine neoplasms (NENs). The aim of the present study was to evaluate the immunohistochemical expression of SSTR2 and SSTR5 in gastrointestinal NENs and goblet cell adenocarcinomas and the correlation of these markers with clinical and morphological factors. The study included 67 patients with NENs and 4 patients with adenocarcinoma ex-goblet cell carcinoid diagnosed between January 2008 and December 2018. Tumors were reclassified according to the 2019 WHO classification. Immunohistochemical staining for chromogranin A, synaptophysin, Ki-67, p53, SSTR2, and SSTR5 were performed in all the cases. The results showed that, G1 and G2
\end{abstract}

Correspondence to: Dr Sorina Maria Taban, Department of Microscopic Morphology-Pathology, ANAPATMOL Research Center, 'Victor Babeș' University of Medicine and Pharmacy of Timisoara, 2 Eftimie Murgu Square, 300041 Timisoara, Romania

E-mail: sorinataban@yahoo.com

${ }^{*}$ Contributed equally

Key words: neuroendocrine, somatostatin receptors, synaptophysin, chromogranin A, adenocarcinoma ex-goblet cell carcinoid, mixed neuroendocrine non-neuroendocrine tumor neuroendocrine tumors were more common SSTR2-positive in comparison with $\mathrm{G} 3$ carcinomas $(\mathrm{P}<0.0001)$. In addition, $33.3 \%$ of neuroendocrine carcinomas and 2 cases of low-grade adenocarcinoma ex-goblet cell carcinoid were SSTR2-positive. Neuroendocrine carcinomas had significantly lower SSTR2 and SSTR5 expression compared with well-differentiated neuroendocrine tumors $(\mathrm{P}=0.0130 ; \mathrm{P}=0.0437$, respectively). The SSTR2 expression in the early tumor stages was $100 \%$, more often than in advanced stages $(55.6 \%$; $\mathrm{P}=0.0011)$. The results demonstrated the decrease in SSTR2 expression with increasing malignancy and tumor stage. The SSTR2-positive expression in neuroendocrine carcinomas and adenocarcinoma ex-goblet cell carcinoid provides evidence for the benefits of somatostatin analog treatment associated with surgery and chemotherapy.

\section{Introduction}

One of the most important changes in the 5th edition of the 2019 WHO classification of tumors of the digestive system is the classification system of neuroendocrine neoplasms (NENs). NENs arise in different organs and epithelial tissues and include numerous entities with variate etiologies, clinical and morphological aspects, and different evolutions (1). Over the years, the variable classification methods used to evaluate these tumors generated a considerable amount of confusion regarding the terminology and histology of NENs.

In November 2017, a dedicated consensus meeting was held in Lyon at the International Agency for Research on Cancer (IARC), under the auspices of the WHO Classification of Tumors Group (2). The consensus conference established a unitary classification system for NENs, that was later published in the 2018 WHO classification guide.

This novel system designed two new categories: neuroendocrine tumors that are well-differentiated (NETs) and were initially described as carcinoid tumors of the gastrointestinal 
tract and a second category for neuroendocrine carcinomas (NECs) that are poorly differentiated and, although they positive for most neuroendocrine markers, have a poor prognosis and evolution (3).

The actual classification and the tumor grading algorithm are very similar to the one discussed in the 2017 WHO classification of pancreatic NENs. Therefore, a new category was generated, the well-differentiated grade 3 NETs of the digestive system. The distinction between NETs and NECs with large cells (LCNEC) and small cells (SCNEC) consists of different morphological characteristics $(1,4)$. The presence of both components, low and high grade, in a unique tumor is a strong argument in favor of naming NETs as grade 3 well-differentiated NETs. Mixed tumors, in which each component, neuroendocrine and non-neuroendocrine, represents more than 30 percent of the tumor cells, are termed mixed neuroendocrine-non-neuroendocrine tumors or MiNENs (2).

Over the last 2-3 years, genetic studies have shown that the genetic mutations in neuroendocrine tumor cells with extra-pancreatic origin (especially in those of the gastrointestinal tract) are very similar to those of the pancreas. In gastrointestinal NECs, TP53 and RB1 mutations are frequently encountered, similar to pancreatic and pulmonary NECs, but absent in NETs. MEN1, DAXX and ATRX mutations are characteristic of well-differentiated NETs $(5,6)$.

Aside from the morphological and molecular aspects, G3 NETs and NECs also differ from a clinical point of view. Platinum-containing chemotherapy is successfully used in NECs, sometimes with noteworthy results in SCNECs. Despite this aspect, the observation was stated that some patients do not respond to this therapy but have longer survival and better outcome than patients that were responsive to platinum-based chemotherapy. This subgroup of patients was subsequently diagnosed with G3 NETs (1).

Gastroenteropancreatic NENs are characterized by the overexpression of somatostatin receptors (SSTRs) 2 and 5, a family of $\mathrm{G}$ protein-coupled receptors present in neuroendocrine cells $(7,8)$. Somatostatin is a cyclic neuropeptide that is ubiquitously expressed in humans, acting as an inhibitor of exocrine and endocrine secretions on target organs. It exerts its biological effects by binding to five specific high-affinity receptors on the cell surface (9). Somatostatin then activates the second messenger system with a wide range of actions: inhibition of adenylate cyclase, activation of calcium channels, stimulation of phosphotyrosine phosphatase or MAPK kinase activity (10). The expression of these markers is the foundation for somatostatin analogue therapy.

Adenocarcinoma ex-goblet cell carcinoid (AGCC), a term proposed by Klimstra et al (1) and Tang et al (11) or mixed goblet cell carcinoid-adenocarcinoma (12) is an enigmatic entity, an amphicrine tumor with glandular/mucinous and neuroendocrine differentiation (at least, focal differentiation). Tang et al revealed that these tumors are adenocarcinomas or AGCC, but not NECs (11). It seems that focal immunoreactions to chromogranin $\mathrm{A}(\mathrm{CgA})$ and other neuroendocrine markers support this hypothesis (12-14). In the current WHO classification, these neoplasms are classified as goblet cell adenocarcinomas (15).
Currently, only a few studies have followed immunohistochemical (IHC) SSTR expression in gastrointestinal NENs, although immunohistochemistry allows precise cellular localization of SSTRs. In this study, the aims were to evaluate the IHC expression of SSTR2 and SSTR5 in gastrointestinal NENs, MiNENs and AGCCs, as well as to correlate the expression of these markers with clinical and morphological factors that impact the overall prognosis, outcome and treatment of the patients.

\section{Patients and methods}

Patient data. The retrospective study included 76 patients with gastrointestinal NENs confirmed by histology and immunohistochemistry at the Pathology Laboratory of Timis County Emergency Clinical Hospital (Timisoara, Romania) from January 2008 to December 2018. The cases were selected according to histopathological diagnosis and tissue material available for pathological evaluation and IHC reactions. In 5 cases, the examined tissue material was not sufficient to perform the required number of sections for IHC investigation. Our study batch consisted of 52 gastrointestinal tumors (endoscopic biopsies, specimens of polypectomy and surgical samples) and 19 cases of liver metastases in the absence of evident primary disease. The median age of the patients (37 men and 34 women) was 59.9 years. Patient clinical and pathological characteristics are summarized in Table I.

The study was conducted in accordance with Declaration of Helsinki, in compliance with good clinical practice, and was approved by the Ethics Committee of 'Pius Brinzeu' Emergency Clinical County Hospital and Victor Babes University of Medicine and Pharmacy Timisoara (no. 20 b/2015 extended in 2019). Written informed consent was obtained from each patient included in our study.

Histological and IHC interpretation. Tumors were reclassified according to the 2019 WHO classification (Table II). IHC stains were performed in all 71 cases. The specimens were fixed in $10 \%$ neutral-buffered formalin for a maximum of $24 \mathrm{~h}$ at room temperature, paraffin-embedded and sectioned at 3- to $4-\mu \mathrm{m}$. IHC staining was performed with a Leica Bond-Max, which is an automatic and continuous access slide-staining system that simultaneously processes IHC protocols, using a Bond Polymer Refine Detection Kit (Leica Biosystems Newcastle). Ki67 (clone MM1, catalog no. PA0118), CgA (clone 5H7, catalog no. PA0515), synaptophysin (Syn) (clone 27G12, catalog no. PA0299) and p53 (clone DO-7, catalog no. PA0057) antibodies from Leica with ready-to-use (RTU) kits following the manufacturer protocols were used. For the IHC detection of SSTR2 and SSTR5 antibodies, the following protocol was performed: tissues were deparaffinized and pre-treated with the Epitope Retrieval Solution 1 at $98^{\circ} \mathrm{C}$ for $20 \mathrm{~min}$. Specimens were then incubated with the primary antibody for $30 \mathrm{~min}$ at a dilution of 1:150 for SSTR2 (clone UMB1, Abcam, catalog no. ab134152) and 1:125 for SSTR5 (clone UMB4, Abcam, catalog no. ab109495), followed by visualization with a Leica Bond Polymer Refine Detection kit for $20 \mathrm{~min}$ at room temperature. Finally, the sections were washed in water and counterstained with hematoxylin. Appropriate negative and positive controls were generated with satisfactory staining. 
Table I. Clinicopathological characteristics of the patients with gastrointestinal NENs, MiNENs and AGCCs.

\begin{tabular}{|c|c|c|}
\hline Clinicopathological characteristics & No. & $\%$ \\
\hline \multicolumn{3}{|l|}{ Sex } \\
\hline Male & 37 & 52.1 \\
\hline Female & 34 & 47.9 \\
\hline \multicolumn{3}{|l|}{ Age at diagnosis (years) } \\
\hline$<20$ & 2 & 2.8 \\
\hline $20-29$ & 1 & 1.4 \\
\hline $30-39$ & 3 & 4.2 \\
\hline $40-49$ & 7 & 9.9 \\
\hline $50-59$ & 17 & 23.95 \\
\hline $60-69$ & 24 & 33.8 \\
\hline$\geq 70$ & 17 & 23.95 \\
\hline \multicolumn{3}{|l|}{ Tumor location } \\
\hline Stomach & 10 & 14.1 \\
\hline Duodenum & 2 & 2.8 \\
\hline Small intestine & 10 & 14.1 \\
\hline Appendix & 6 & 8.5 \\
\hline Right colon & 11 & 15.5 \\
\hline Left colon (including rectum) & 13 & 18.3 \\
\hline Hepatic metastasis & 19 & 26.7 \\
\hline \multicolumn{3}{|l|}{ Tumor grade } \\
\hline G1 & 28 & 39.4 \\
\hline $\mathrm{G} 2$ & 21 & 29.6 \\
\hline G3 & 22 & 31 \\
\hline \multicolumn{3}{|l|}{ Tumor type } \\
\hline NET & 52 & 73.2 \\
\hline NET G1 & 27 & 38 \\
\hline NET G2 & 18 & 25.4 \\
\hline NET G3 & 7 & 9.8 \\
\hline NEC & 12 & 17 \\
\hline SCNEC & 3 & 4.25 \\
\hline LCNEC & 9 & 12.7 \\
\hline MiNEN & 3 & 4.25 \\
\hline AGCCs & 4 & 5.6 \\
\hline AGCC G1 & 1 & 1.4 \\
\hline AGCC G2 & 1 & 1.4 \\
\hline AGCC G3 & 2 & 2.8 \\
\hline
\end{tabular}

G, grade; NET, neuroendocrine tumor; NEC, neuroendocrine carcinoma; SCNEC, small cell neuroendocrine carcinoma; LCNEC, large cell neuroendocrine carcinoma; MiNEN, mixed neuroendocrine non-neuroendocrine neoplasm; AGCC, adenocarcinoma ex-goblet cell carcinoid.

The slides were examined under the Eclipse E200 Nikon microscope.

Cases were scored as focal or diffuse positive for cytoplasmic staining of the tumor cells with CgA and Syn antibodies. The proliferation index Ki-67 represents the percentage of cells with nuclear expression of a total of 500 tumoral cells in hot-spots. In biopsies where only a small number of tumor cells were present, all tumor cells were counted. Tumors with a mitotic rate $>20 \%$ and a $\mathrm{Ki}-67$ proliferation index of $>20 \%$ were IHC evaluated for the expression of p53. The immunoexpression was considered positive if intense nuclear staining was present in $>25 \%$ of the tumor cells. Strongly positive p53 was considered abnormal and indicated mutations in the TP53 gene $(16,17)$.

The expression of SSTR2 was evaluated according to the system proposed by Volante et al (18). Therefore, the absence of the IHC expression was graded with 0 , a cytoplasmic expression, either focal or diffuse, with 1 , and the presence of a membranous reactivity in $<50 \%$ of the tumor cells (irrespective of the presence of cytoplasmic staining) with a score 2 . The membranous expression in $>50 \%$ of tumor cells (not taking the cytoplasmic staining into consideration) was scored as 3 . The cases that scored 0 and 1 were considered negative, and those with 2 and 3 were positive. The immunoreactions for SSTR 5 were negative if $<10 \%$ of the tumor cells presented cytoplasmic or membranous staining, and positive if $>10 \%$ had a cytoplasmic or membranous reactivity.

Statistical analysis. Statistical analyses were performed with GraphPad Prism 9.0 (GraphPad Software, Inc.). Descriptive statistics of qualitative data such as patient general data, site, grade and type are expressed as numbers and percentages. The results of SSTR2 and SSTR5 expression analysis were compared in terms of various clinicopathological data, including tumor location, grade, type and stage. Statistical evaluation was performed utilizing $\chi^{2}$ tests. $\mathrm{P}<0.05$ was considered to indicate a statistically significant difference.

\section{Results}

Patient characteristics. According to the new WHO classification of 2019 (1), 52 well-differentiated NETs, 12 NECs with small or large cells, 3 MiNENs and 4 cases of AGCC were included in the study (Table I). The median age of the patients ( 37 men and 34 women) was 59.9 years. Although the incidence of NETs increases significantly after the age of 50, 3 patients with NET were under 30 years of age. In addition, 19 metastatic NETs that were diagnosed after hepatic surgery or for which core biopsy was performed were identified. The neuroendocrine nature of the tumors that were included herein was confirmed by documenting a positive focal or diffuse expression for at least one neuroendocrine marker (CgA or Syn).

Primary NENs were more frequently diagnosed in the left colon including the rectum $(18.3 \%)$, the right colon $(15.5 \%)$ and in the small intestine (14.1\%); however, the most frequent tumors were hepatic metastasis of NEN (26.7\%) (Table I). The majority of NENs were well-differentiated tumors (39.4\%), although in 6 cases, hepatic metastasis was present at the time of the diagnosis (Table I).

In the 2019 WHO classification, both well-differentiated G3 NETs and G3 NECs are characterized by a mitotic rate of $>20 \%$ and a Ki-67 proliferation index of $>20 \%$. The histological examination of the NECs revealed solid sheets or trabeculae of large cells with pale eosinophilic cytoplasm, vesicular, pleomorphic nuclei with large nucleoli and a high 
Table II. Classification and grading criteria for NENs of the gastrointestinal tract (1).

\begin{tabular}{lllcc}
\hline Terminology & \multicolumn{1}{c}{ Differentiation } & Grade & Mitotic rate $^{\mathrm{a}}$ & Ki-67 index $^{\mathrm{b}}$ \\
\hline NET, G1 & Well-differentiated & Low & $<2$ & $3-20 \%$ \\
NET, G2 & & Intermediate & $2-20$ & $>20 \%$ \\
NET, G3 & High & High & $>20$ & $>20 \%$ \\
SCNEC & Poorly differentiated & & $>20$ & $>20 \%$ \\
LCNEC & & Variable & Variable & Variable \\
MiNEN & Well or poorly differentiated & & \\
\hline
\end{tabular}

${ }^{\mathrm{a}}$ Mitotic rate, the number of mitosis $/ 2 \mathrm{~mm}^{2} .{ }^{\mathrm{b}} \mathrm{Ki}-67$ index, counting $\geq 500$ cells in the regions of highest labelling (hot-spots) which are identified at scanning magnification. NENs, neuroendocrine neoplasms; NET, neuroendocrine tumor; NEC, neuroendocrine carcinoma; SCNEC, small cell neuroendocrine carcinoma; LCNEC, large cell neuroendocrine carcinoma; MiNEN, mixed neuroendocrine non-neuroendocrine neoplasm.

Table III. The correlation between SSTR2/SSTR5 expression and clinicomorphological factors.

\begin{tabular}{|c|c|c|c|}
\hline Clinicopathological factors & No. & $\mathrm{SSTR}^{+}$cases $\mathrm{n}(\%)$ & $\mathrm{SSTR}^{+}$cases n $(\%)$ \\
\hline \multicolumn{4}{|l|}{ Tumor location } \\
\hline Stomach & 10 & $8(80)$ & $3(30)$ \\
\hline Duodenum & 2 & $0(0)$ & $0(0)$ \\
\hline Small intestine & 10 & $10(100)$ & $5(50)$ \\
\hline Appendix & 6 & $6(100)$ & $1(16.7)$ \\
\hline Right colon & 11 & $5(45.5)$ & $3(27.3)$ \\
\hline Left colon (including rectum) & 13 & $7(53.8)$ & $5(38.5)$ \\
\hline Hepatic metastases & 19 & $11(57.9)$ & $3(15.8)$ \\
\hline \multicolumn{4}{|l|}{ Tumor grading } \\
\hline G1 & 28 & $27(96.4)$ & $10(35.7)$ \\
\hline G2 & 21 & $5(71.4)$ & $7(33.3)$ \\
\hline G3 & 22 & $5(22.7)$ & $3(13.6)$ \\
\hline \multicolumn{4}{|l|}{ Tumor type } \\
\hline NET & 52 & $39(75)$ & $17(32.7)$ \\
\hline NET G1 & 27 & $26(96.3)$ & $10(37)$ \\
\hline NET G2 & 18 & $12(66.7)$ & $6(33.3)$ \\
\hline NET G3 & 7 & $1(14.3)$ & $1(14.3)$ \\
\hline NEC & 12 & $4(33.3)$ & $2(16.7)$ \\
\hline MiNEN & 3 & $2(66.7)$ & $1(33.3)$ \\
\hline AGCCs & 4 & & \\
\hline $\mathrm{AGCC} \mathrm{G} 1+\mathrm{G} 2$ & 2 & $2(100)$ & $0(0)$ \\
\hline AGCC G3 & 2 & $0(0)$ & $0(0)$ \\
\hline \multicolumn{4}{|l|}{ Tumor stage } \\
\hline I & 7 & $7(100)$ & $3(42.9)$ \\
\hline II & 9 & $9(100)$ & $4(44.4)$ \\
\hline III & 23 & $13(56.5)$ & $8(34.8)$ \\
\hline IV & 22 & $12(54.5)$ & $3(13.6)$ \\
\hline
\end{tabular}

SSTR, somatostatin receptor; G, grade; NET, neuroendocrine tumor; NEC, neuroendocrine carcinoma; SCNEC, small cell neuroendocrine carcinoma; LCNEC, large cell neuroendocrine carcinoma; MiNEN, mixed neuroendocrine non-neuroendocrine neoplasm; AGCC, adenocarcinoma ex-goblet cell carcinoid.

mitotic rate (LCNEC) or areas of small cells with scant cytoplasm and hyperchromatic nuclei (SCNEC), tumor necrosis and occasional desmoplastic stroma. Although well-differentiated G3 NETs are difficult to identify on histology alone, distinct areas of organoid pattern of tumor cells and foci of tumor cells with relatively monomorphic 

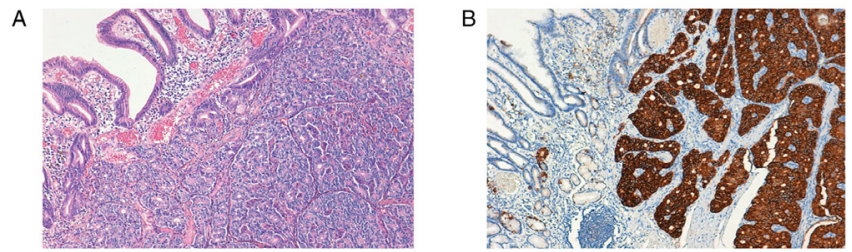

C
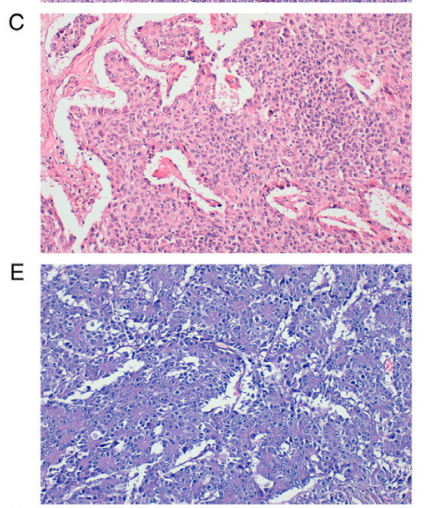

$\mathrm{G}$

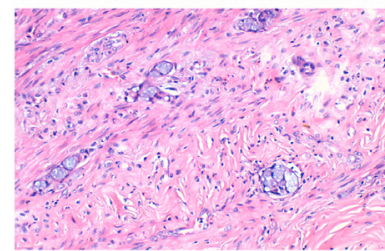

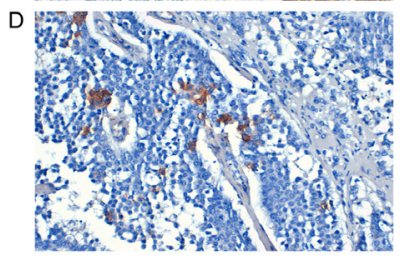

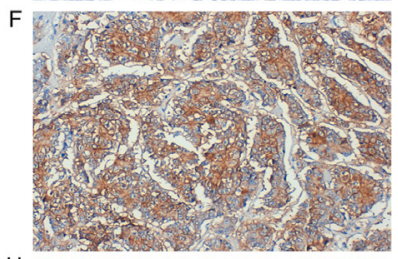

$\mathrm{H}$

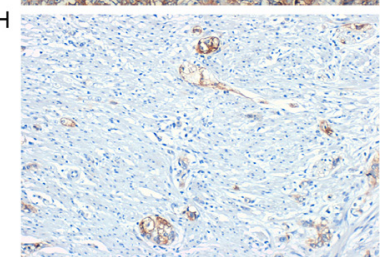

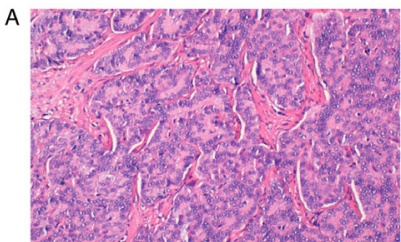

$\mathrm{C}$
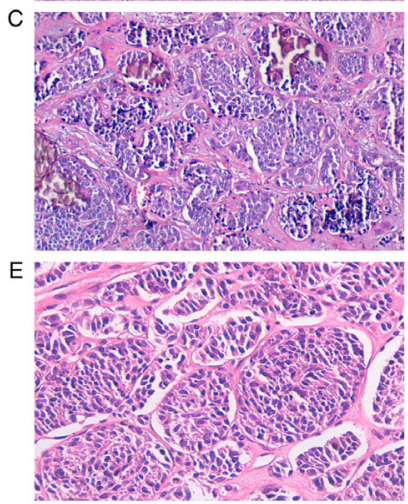

G

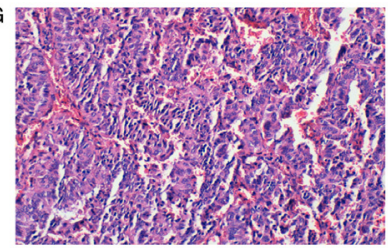

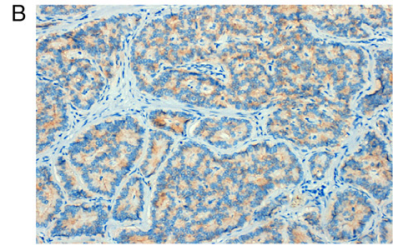
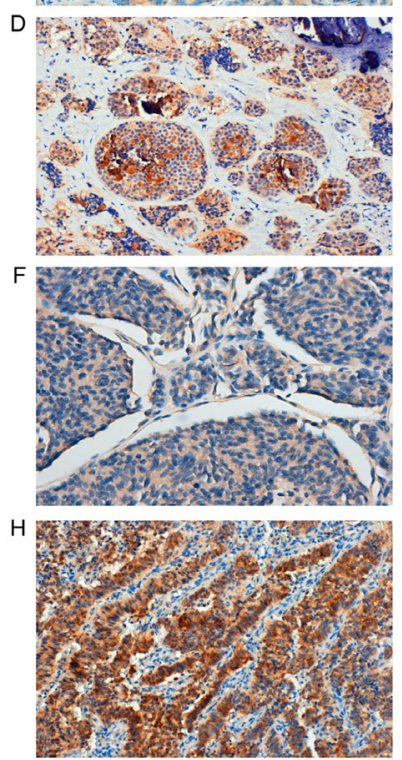

Figure 1. Expression of SSTR2 in NETs. (A) Well-differentiated NET, G2. (B) Strong SSTR2 positive staining (score 3), magnification x10. (C) Well-differentiated NET, G2. (D) SSTR2 positive staining (score 2), magnification $x 40$. (E) LCNEC. (F) Strong SSTR2-positive staining (score 3), magnification x20. (G) Appendiceal AGCC. (H) SSTR2-positive staining (score 3), x20 magnification. SSTR, somatostatin receptor; G, grade NET, neuroendocrine tumor; LCNEC, large cell neuroendocrine carcinoma; AGCC, adenocarcinoma ex-goblet cell carcinoid.

nuclei are highly suggestive of this type of tumor. To correctly diagnose and classify these tumors, immunoreaction for $\mathrm{p} 53$ was performed. Tumors with $>25 \%$ intensely positive cells for the above-mentioned marker were classified as G3 NEC. Two cases of MiNEN were identified in the left colon and one with a gastric location. According to the 2019 WHO recommendations, 1 case of G1 adenocarcinoma in association with LCNEC and 2 cases of G2 adenocarcinoma with G2 well-differentiated NETs were identified. Additionally, 4 cases of AGCCs were included in the study. According to the most recent WHO classification system, 2 cases of appendicular G1 and G2 AGCC and 2 cases of G3 AGCC in the cecum/right colon were identified.

SSTR2/SSTR5 expression and clinicomorphological factors. The immunoreactions for SSTR 2 demonstrated a membranous expression of variable intensity in 47 cases $(66.2 \%)$ (Table III; Fig. 1). The cytoplasmic expression was found in 6 cases $(8.5 \%)$ that were scored 1 (negative). No case with nuclear SSTR2 expression occurred.

In total, $28.2 \%$ of the tumors presented a positive cytoplasmic or membranous expression for SSTR5 (20 cases), with variable intensity (Fig. 2).

To simplify the interpretation, NEC, MiNEN and AGCC were considered together in the final analysis (Table IV). NETs and NECs that showed a positive staining for SSTR2,
Figure 2. Expression of SSTR5 in NETs. (A) Well-differentiated NET, G1. (B) SSTR5-positive staining, magnification x20. (C) Well-differentiated NET, G2 with microcalcifications. (D) SSTR5-positive staining, magnification x20. (E) Well-differentiated NET, G3. (F) Weak SSTR5-positive staining, magnification x40. (G) LCNEC. (H) Strong SSTR5-positive staining, $x 20$ magnification. SSTR, somatostatin receptor; G, grade; NET, neuroendocrine tumor; LCNEC, large cell neuroendocrine carcinoma.

were more frequently found in the small intestine $(100 \%$ of the cases), appendix (100\% of the cases) and the stomach (66,66\% of the cases). In addition, $50 \%$ of the tumors in the small intestine were also positive for SSTR5. Well- and moderately differentiated tumors exhibited significantly more common SSTR2 in comparison with G3 tumors $(\mathrm{P}<0.0001$; Fig. 3). In the present study group, $33.3 \%$ of NECs and $14.3 \%$ of well-differentiated G3 NETs expressed SSTR2 (Table III). Both cases of low-grade AGCC were SSTR2-positive. Poorly differentiated tumors (NEC+MiNEN+AGCC) had significantly lower SSTR2 and SSTR5 expression compared with NETs $(\mathrm{P}=0.0130$ and $\mathrm{P}=0.0437$, respectively).

The expression rate of SSTR2 in tumors of stage I and II was $100 \%$, which was more frequent than tumors of stage III and IV (55.6\%; P=0.0011; Fig. 4). NETs and NECs were diagnosed late, in the advanced stages of the disease (stage III, $37.7 \%$ and stage IV, $36.1 \%$ vs. stage I, $11.5 \%$ and stage II, $14.8 \%$ ).

\section{Discussion}

NENs represent a heterogeneous group of tumors, with various clinical presentations due to hormonal secretion from the tumor cells. Patients with neuroendocrine carcinomas (NENs) often exhibit flushing, diarrhea, bronchospasm, or suffer from cardiovascular/valvular disease $(19,20)$. The new category 
Table IV. SSTR2 and SSTR5 expression and clinicopathological characteristics.

\begin{tabular}{|c|c|c|c|c|c|c|c|}
\hline $\begin{array}{l}\text { Clinicopathological } \\
\text { characteristic }\end{array}$ & No. & $\mathrm{SSTR}^{+}{ }^{+}$cases n $(\%)$ & $\chi^{2}$ value & P-value & $\mathrm{STR}^{+}$cases n $(\%)$ & $\chi^{2}$ value & P-value \\
\hline \multicolumn{8}{|l|}{ Tumor location } \\
\hline Stomach + duodenum & 12 & $8(66.66)$ & \multirow[t]{5}{*}{1.252} & \multirow[t]{5}{*}{0.869} & $3(25)$ & \multirow{5}{*}{ Non-valid } & \\
\hline Small intestine & 10 & $10(100)$ & & & $5(50)$ & & \\
\hline Appendix & 6 & $6(100)$ & & & $1(16.7)$ & & \\
\hline Colon & 24 & $12(50)$ & & & $8(33.33)$ & & \\
\hline Hepatic metastases & 19 & $11(57.9)$ & & & $3(15.8)$ & & \\
\hline \multicolumn{8}{|l|}{ Tumor grade } \\
\hline G1 & 28 & $27(96.4)$ & \multirow[t]{3}{*}{30.27} & \multirow[t]{3}{*}{$<0.0001$} & $10(35.7)$ & \multirow[t]{3}{*}{3.361} & \multirow[t]{3}{*}{0.1863} \\
\hline G2 & 21 & $15(71.4)$ & & & $7(33.3)$ & & \\
\hline G3 & 22 & $5(22.7)$ & & & $3(13.6)$ & & \\
\hline \multicolumn{8}{|l|}{ Tumor type } \\
\hline NET & 52 & $39(75)$ & \multirow[t]{2}{*}{6.174} & \multirow[t]{2}{*}{0.0130} & $17(32.7)$ & \multirow[t]{2}{*}{4.068} & \multirow[t]{2}{*}{0.0437} \\
\hline NEC+MiNEN+AGCC & 19 & $8(42.10)$ & & & $3(11.53)$ & & \\
\hline \multicolumn{8}{|l|}{ Tumor stage } \\
\hline $\mathrm{I}+\mathrm{II}$ & 16 & $16(100)$ & \multirow[t]{2}{*}{3.253} & \multirow[t]{2}{*}{0.0011} & $7(43.8)$ & \multirow[t]{2}{*}{2.115} & \multirow[t]{2}{*}{0.1459} \\
\hline III+IV & 45 & $25(55.6)$ & & & $11(24.4)$ & & \\
\hline
\end{tabular}

SSTR, somatostatin receptor; G, grade; NET, neuroendocrine tumor; NEC, neuroendocrine carcinoma; MiNEN, mixed neuroendocrine non-neuroendocrine neoplasm; AGCC, adenocarcinoma ex-goblet cell carcinoid.
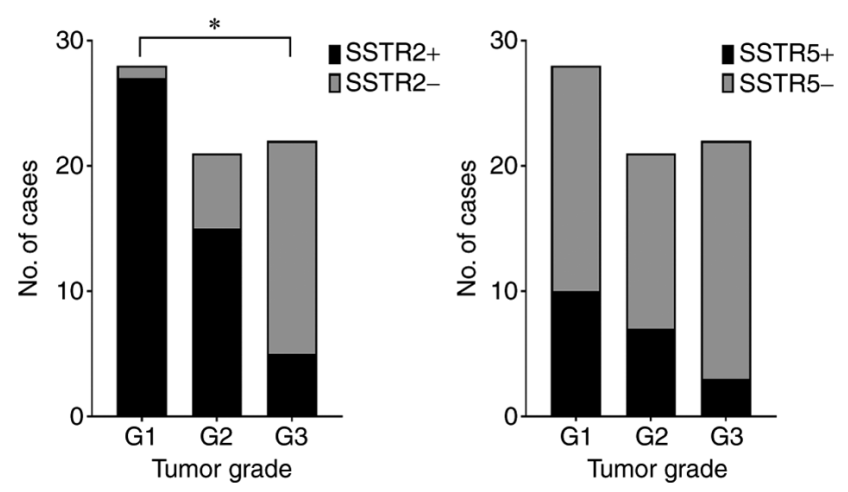

Figure 3. Expression of SSTR2 and SSTR5 according to tumor grade. SSTR, somatostatin receptor; ${ }^{+}$, positive expression; ${ }^{*}$, significant correlation.

of G3 neuroendocrine tumor (NET) was first introduced in the 2017 WHO classification of pancreatic tumors and later extended to all gastrointestinal NENs in 2019 (G1, G2 and G3 well-differentiated NEN) (1).

Epidemiological studies indicated that the incidence of NENs has been on the increase, especially for cases diagnosed in the early, asymptomatic stages of the disease. The increase of incidence may be due to earlier detection with the increased use of endoscopy (20). According to national cancer registries in Western Europe and the US National Cancer Institute, Surveillance, Epidemiology and End Results, the most significant increase in incidence was found for gastric and rectal NENs. The small intestinal and cecal NENs showed only a discrete increase. The overall estimated annual incidence of gastroenteropancreatic NENs is between 3.6 and 3.9 per 100,000 population (21-23). In line with these findings, the
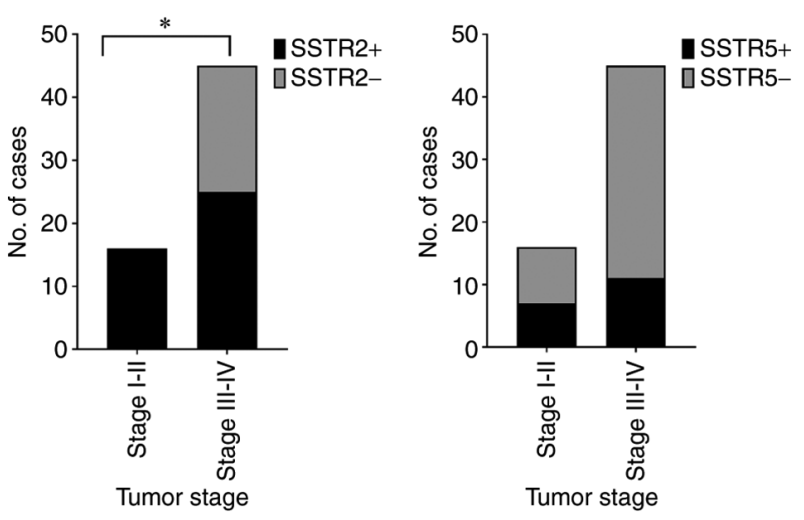

Figure 4. Expression of SSTR2 and SSTR5 according to tumor stage. SSTR, somatostatin receptor; ${ }^{+}$, positive expression; ${ }^{*}$, significant correlation.

present study demonstrated that the most common locations for primary NENs and mixed neuroendocrine non-neuroendocrine neoplasm (MiNENs) were the left colon and rectum (18.3\%).

A significant increase was observed in NENs incidence in patients older than 50 years. The patients were often diagnosed between 60 and 69 years (33.8\%), although 3 patients presented at a young age ( 2 patients aged 19 years and 1 patient was 25 years of age). Although endoscopy is an investigation frequently used in our hospital, the study revealed that most NENs, MiNENs and adenocarcinoma ex-goblet cell carcinoids (AGCCs) were diagnosed and surgically removed in the late stages of the disease (stage III, $37.7 \%$ and stage IV, $36.1 \%$ compared with stage I, $11.5 \%$ and stage II, $14.8 \%$ ). 
NETs located in the stomach, duodenum (excepting gastrinomas), pancreas and rectum, with sizes $\leq 10 \mathrm{~mm}$ and considered G1 in the WHO classification, are considered by some authors 'early' NETs. These patients have an excellent prognosis. Endoscopic mucosal or submucosal resection is recommendable 'early NETS' (some authors include tumors that are $<20 \mathrm{~mm}$ ), with no invasion of the muscularis propria (pT1) and no vascular invasion (V0, L0) (24). In the current study group, only three such tumors were diagnosed after polypectomy and classified as well-differentiated G1 NETs, stage I.

In the case of localized NENs, it is recommendable to choose surgery adapted to tumor type, size, or multifocality of the lesion. Hepatic metastases of NENs require a multidisciplinary approach and are very challenging for surgeons, pathologists, radiologists, oncologists and nuclear medicine physicians $(20,25)$.

SSTR positron emission tomography/computed tomography (PET/CT) using 68Ga-labeled somatostatin analogs is an important method of evaluating the SSTR status in NENs (26,27). At present, few studies have assessed the IHC expression of SSTR in NENs, although IHC allows the correct identification of molecular targets in tumor cells and evaluation of different targeted therapeutic approaches. Patients with SSTR-positive tumors that are both advanced and aggressive are optimal candidates for peptide receptor radionuclide therapy (PRRT), increasing the overall survival rate and quality of life (28).

In the present study, the IHC expression for SSTR2 was predominantly membranous, complete or incomplete, in 47 cases $(66.2 \%)$, and $28.2 \%$ of the tumors (20 cases) being positive for SSTR5, with a cytoplasmic or membranous expression of variable intensity. In addition, the co-expression of the two markers in 17 cases $(23.9 \%)$ was identified much more often in well-differentiated G1 (58.8\%) and G2 (29.4\%) NETs.

NETs and NECs that have a positive expression for SSTR2 are strongly correlated with locations such as the small bowel (100\% of the cases), appendix (100\% of cases) and stomach ( $80 \%$ of cases). In addition, $50 \%$ of tumors from the small intestine are positive for SSTR5.

Some studies reported that SSTR2 and SSTR5 expression showed an inverse correlation with neuroendocrine tumor grade. Low to intermediate-grade tumors had increased SSTR expression compared with high-grade tumors $(29,30)$. In line with these studies, our results showed that well-differentiated G1 and G2 NETs express SSTR2 and SSTR5 more frequently compared to high-grade NETs (96.3 and $66.7 \%$ compared with 14.3\%). A significant decrease was observed in SSTR2 expression with increasing malignancy in gastrointestinal NENs $(\mathrm{P}<0.0001)$.

In the current study group $33.3 \%$ of NECs expressed SSTR 2 compared to $14.3 \%$ of the well-differentiated G3 NETs. Two cases of LCNECs presented a positive IHC expression for SSTR2 and SSTR5. Although our results are noteworthy, recent studies revealed the importance of systemic treatment such as somatostatin analogs, chemotherapy, PRRT or 'sandwich' chemo-PRRT $(31,32)$.

Both cases of appendiceal low-grade AGCCs expressed SSTR2. Although these tumors have a neuroendocrine differentiation indicated by the positive expression of at least one neuroendocrine marker (predominantly focal), the latest WHO classification lists these tumors as carcinomas and not NETs (33). Scientific data are scarce despite some studies proving the severe outcome of patients with AGCCs. According to NANETS 2020 consensus guidelines (34) in limited disease, appendectomy is advised for tumors $<1 \mathrm{~cm}$. Right hemicolectomy with lymph node dissection is advised for tumors between 1 and $2 \mathrm{~cm}$ or $>2 \mathrm{~cm}$. For advanced cases, there are no guidelines, although some authors recommend the association of surgery and treatment with everolimus and octreotide LAR.

By analyzing the immunoreactivity for SSTR2 and SSTR5 according to tumor stage $(1,35)$, it was clear that the markers showed more frequently positive reactions in the earlier stages of the disease $(100 \%$ for SSTR2 and $43.8 \%$ for SSTR5) in comparison with advanced stages (55.6\% for SSTR2 and $24.4 \%$ for SSTR5). SSTR2 expression was significantly more often positive in the first two stages of the disease $(\mathrm{P}=0.0011)$. However, other studies reveal contradictory data. Srirajaskanthan et al (30) found an association between the SSTR2 expression and TNM stage I and II, but not between SSTR5 expression and tumor stage. Other studies showed no connection between SSTR expression and tumor location, functional status, and TNM staging. However, those previous studies mainly focused on particular types of gastroenteropancreatic NENs or only on pancreatic tumors (36-39).

The current study has some limitations due to the reduced number of some particular neoplasms, including G3 NETs and MiNENs. Another drawback of the present study is the absence of clinical follow-up and survival information, but there is no single cancer registry in Romania. Despite these limitations, a large number of heterogenic gastrointestinal tumors were included. In addition, each tumor was re-evaluated according to the latest WHO classification, monoclonal antibodies were used and the staining protocols for SSTR2 and SSTR5 were optimized thoroughly in our laboratory. The results allow us to make firm conclusions regarding the association between SSTR expression and clinical and pathological characteristics of patients with gastrointestinal NENs.

In summary, immunohistochemistry is a useful and reliable method for the detection of SSTRs in gastrointestinal NENs and MiNENs, allowing the determination of the SSTR profile in the clinical setting. Immunohistochemical expression of SSTRs varied considerably depending on the tumor location, with higher values of SSTR2 in NENs originating from the small bowel, appendix, and stomach. SSTR2 expression is frequent in a range of NENs, MiNENs, and AGCCs. The positive expression of SSTR2 in NECs and AGCCs provides evidence for the usefulness of somatostatin analog treatment associated with surgery and chemotherapy. SSTR2 and SSTR5 IHC markers significantly correlate with tumor grade and tumor stage and can be considered potential prognostic factors. In our opinion, the evaluation of IHC expression of SSTRs should be encouraged in all NENs, MiNENs, and the particular group of AGCCs.

\section{Acknowledgements}

Not applicable. 


\section{Funding}

No funding is received.

\section{Availability of data and materials}

All data generated or analyzed during this study are included in this published article.

\section{Authors' contributions}

OP contributed to the conception of the study, collected, analyzed and interpreted data from the literature and critically revised the manuscript. SMT contributed to the conception of the study, performed the literature research, drafted the manuscript and is responsible for confirming the authenticity of all the raw data. SP contributed to the conception of the study, performed the literature research, drafted the manuscript and is responsible for confirming the authenticity of all the raw data. ADP contributed to the interpretation of the data from the literature, collected, analyzed and interpretated the data corresponding to the patient and critically revised the manuscript. $\mathrm{RAB}$ contributed to the interpretation of the data from the literature and critically revised the manuscript. MC collected, analyzed and interpretated the data corresponding to the patient and critically revised the manuscript. AAP performed the literature research, selected the included studies, analyzed and interpretated the data and drafted the manuscript. ALCD contributed to the conception of the study, performed the literature research, selected the included studies, analyzed and interpretated the data and drafted the manuscript. All authors read and approved the final manuscript.

\section{Ethics approval and consent to participate}

The study was conducted in accordance with Declaration of Helsinki, in compliance with good clinical practice, and was approved by the Ethics Committee of 'Pius Brinzeu' Emergency Clinical County Hospital and Victor Babes University of Medicine and Pharmacy Timisoara (no. 20 b/2015 extended in 2019). Written informed consent was obtained from each patient included in our study.

\section{Patient consent for publication}

Not applicable.

\section{Competing interests}

The authors declare that they have no conflicts of interest or competing interests.

\section{Authors' information}

Oana Popa: ORCID: 0000-0003-3883-2438; Sorina Maria Taban: ORCID: 0000-0002-3971-2756; Stelian Pantea: ORCID: 0000-0002-6048-6909; Andrei Dorel Plopeanu: ORCID: 0000-0002-4900-4809; Robert Alexandru Barna: ORCID: 0000-0003-4634-969X; Marioara Cornianu: ORCID: 0000-0001-5675-5339; Anca-Ariana Pascu: ORCID:
0000-0002-0027-1674; Alis Liliana Carmen Dema: ORCID: 0000-0003-0767-2718.

\section{References}

1. Klimstra DS, Kloppel G, La Rosa S and Rindi G: Digestive System Tumours. In: WHO Classification of Tumours. 5th edition. Vol 1. IARC, Lyon, 2019.

2. Rindi G, Klimstra DS, Abedi-Ardekani B, Asa SL, Bosman FT, Brambilla E, Busam KJ, de Krijger RR, Dietel M, El-Naggar AK, et al: A common classification framework for neuroendocrine neoplasms: An international agency for research on cancer (IARC) and World Health Organization (WHO) expert consensus proposal. Mod Pathol 31: 1770-1786, 2018.

3. Klöppel G: Neuroendocrine neoplasms: Dichotomy, origin and classifications. Visc Med 33: 324-330, 2017.

4. Cockburn A and Rege TA: Gastrointestinal neuroendocrine lesions. In: Fenoglio-Preiser' Gastrointestinal Pathology. 4th edition. Wolters Kluwer, Alphen aan den Rijn, pp3300-3512, 2017.

5. Mafficini A and Scarpa A: Genetics and epigenetics of gastroenteropancreatic neuroendocrine neoplasms. Endocr Rev 40: 506-536, 2019.

6. Crona J and Skogseid B: GEP-nets update: Genetics of neuroendocrine tumors. Eur J Endocrinol 174: R275-R290, 2016.

7. Cakir M, Dworakowska D and Grossman A: Somatostatin receptor biology in neuroendocrine and pituitary tumours: Part 1-Molecular pathways. J Cell Mol Med 14: 2570-2584, 2010.

8. Klomp MJ, Dalm SU, de Jong M, Feelders RA, Hofland J and Hofland LJ: Epigenetic regulation of somatostatin and somatostatin receptors in neuroendocrine tumors and other types of cancer. Rev Endocr Metab Disord: Oct 21, 2020 (Epub ahead of print).

9. Barbieri F, Bajetto A, Pattarozzi A, Gatti M, Würth R, Thellung S, Corsaro A, Villa V, Nizzari M and Florio T: Peptide receptor targeting in cancer: The somatostatin paradigm. Int J Pept 2013: 926295, 2013.

10. Hankus J and Tomaszewska R: Neuroendocrine neoplasms and somatostatin receptor subtypes expression. Nucl Med Rev Cent East Eur 19: 111-117, 2016.

11. Tang LH, Shia J, Soslow RA, Dhall D, Wong WD, O'Reilly E, Qin J, Paty P, Weiser MR, Guillem J, et al: Pathologic classification and clinical behavior of the spectrum of goblet cell carcinoid tumors of the appendix. Am J Surg Pathol 32: 1429-1443, 2008.

12. Taggart MW, Abraham SC, Overman MJ, Mansfield PF and Rashid A: Goblet cell carcinoid tumor, mixed goblet cell carcinoid-adenocarcinoma, and adenocarcinoma of the appendix: Comparison of clinicopathologic features and prognosis. Arch Pathol Lab Med 139: 782-790, 2015.

13. Hristov AC, Young RH, Vang R, Yemelyanova AV, Seidman JD and Ronnett BM: Ovarian metastases of appendiceal tumors with goblet cell carcinoidlike and signet ring cell patterns: A report of 30 cases. Am J Surg Pathol 31: 1502-1511, 2007.

14. Reid MD, Basturk O, Shaib WL, Xue Y, Balci S, Choi HJ, Akkas G, Memis B, Robinson BS, El-Rayes BF, et al: Adenocarcinoma ex-goblet cell carcinoid (appendiceal-type crypt cell adenocarcinoma) is a morphologically distinct entity with highly aggressive behavior and frequent association with peritoneal/intra-abdominal dissemination: An analysis of 77 cases. Mod Pathol 29: 1243-1253, 2016.

15. Misdraji J, Carr NJ and Pai Rk: Appendiceal goblet cell adenocarcinoma. In: WHO Classification of Tumours. 5th edition. Vol 1. IARC, Lyon, pp149-151, 2019.

16. Murnyák B and Hortobágyi T: Immunohistochemical correlates of TP53 somatic mutations in cancer. Oncotarget 7: 64910-64920, 2016.

17. Nielsen K, Binderup T, Langer SW, Kjaer A, Knigge P, Grøndahl V, Melchior L, Federspiel B and Knigge U: P53, Somatostatin receptor 2a and Chromogranin A immunostaining as prognostic markers in high grade gastroenteropancreatic neuroendocrine neoplasms. BMC Cancer 20: 27, 2020.

18. Volante M, Brizzi MP, Faggiano A, La Rosa S, Rapa I, Ferrero A, Mansueto G, Righi L, Garancini S, Capella C, et al: Somatostatin receptor type $2 \mathrm{~A}$ immunohistochemistry in neuroendocrine tumors: A proposal of scoring system correlated with somatostatin receptor scintigraphy. Mod Pathol 20: 1172-1182, 2007.

19. Vinik AI and Chaya C: Clinical presentation and diagnosis of neuroendocrine tumors. Hematol Oncol Clin North Am 30: 21-48, 2016. 
20. Wang R, Zheng-Pywell R, Chen HA, Bibb JA, Chen H and Rose JB Management of gastrointestinal neuroendocrine tumors. Clin Med Insights Endocrinol Diabetes 12: 1179551419884058, 2019.

21. Ito T, Sasano H, Tanaka M, Osamura RY, Sasaki I, Kimura W, Takano K, Obara T, Ishibashi M, Nakao K, et al: Epidemiological study of gastroenteropancreatic neuroendocrine tumors in Japan. J Gastroenterol 45: 234-243, 2010.

22. Dasari A, Shen C, Halperin D, Zhao B, Zhou S, Xu Y, Shih T and Yao JC: Trends in the incidence, prevalence, and survival outcomes in patients with neuroendocrine tumors in the united states. JAMA Oncol 3: 1335-1342, 2017.

23. Hofland J, Kaltsas G and de Herder WW: Advances in the diagnosis and management of well-differentiated neuroendocrine neoplasms. Endocr Rev 41: 371-403, 2020.

24. Scherübl H and Cadiot G: Early gastroenteropancreatic neuroendocrine tumors: Endoscopic therapy and surveillance. Visc Med 33: 332-338, 2017.

25. Lewis MA and Hobday TJ: Treatment of neuroendocrine tumor liver metastases. Int J Hepatol 2012: 973946, 2012

26. Hendifar AE, Ramirez RA, Anthony LB and Liu E: Current practices and novel techniques in the diagnosis and management of neuroendocrine tumors of unknown primary. Pancreas 48 : 1111-1118, 2019.

27. Calabrò D, Argalia G and Ambrosini V: Role of PET/CT and therapy management of pancreatic neuroendocrine tumors. Diagnostics (Basel) 10: 1059, 2020.

28. Bartsch DK and Scherübl H: Neuroendocrine tumors of the gastrointestinal tract. Visc Med 33: 321-322, 2017.

29. Righi L, Volante M, Tavaglione V, Billè A, Daniele L, Angusti T, Inzani F, Pelosi G, Rindi G and Papotti M: Somatostatin receptor tissue distribution in lung neuroendocrine tumours: A clinicopathologic and immunohistochemical study of 218 "clinically aggressive' cases. Ann Oncol 21: 548-555, 2010.

30. Srirajaskanthan R, Watkins J, Marelli L, Khan K and Caplin ME: Expression of somatostatin and dopamine 2 receptors in neuroendocrine tumours and the potential role for new biotherapies. Neuroendocrinology 89: 308-314, 2009.

31. Parghane RV, Ostwal V, Ramaswamy A, Bhandare M, Chaudhari V, Talole S, Shrikhande SV and Basu S: Long-term outcome of 'Sandwich' chemo-PRRT: A novel treatment strategy for metastatic neuroendocrine tumors with both FDG- and SSTR-avid aggressive disease. Eur J Nucl Med Mol Imaging 48: 913-923, 2021.

32. Basu S, Parghane RV, Kamaldeep and Chakrabarty S: Peptide receptor radionuclide therapy of neuroendocrine tumors. Semin Nucl Med 50: 447-464, 2020.
33. Nagtegaal ID, Klimstra DS and Washington MK: Tumours of the appendix. Digestive System Tumours. WHO Classification of Tumours, 5th Edition, Edited by WHO Classification of Tumours Editorial Board, 135-156, 2019

34. Kunz PL, Reidy-Lagunes D, Anthony LB, Bertino EM, Brendtro K, Chan JA, Chen H, Jensen RT, Kim MK, Klimstra DS, et al: Consensus guidelines for the management and treatment of neuroendocrine tumors. Pancreas 42: 557-577, 2013.

35. Amin MB, Edge S, Greene F, Byrd DR, Brookland RK, Washington MK, Gershenwald JE, Compton CC, Hess KR, Sullivan DC, et al (eds): AJCC Cancer Staging Manual (8th edition). Springer International Publishing, New York, NY, 2017.

36. Papotti M, Bongiovanni M, Volante M, Allìa E, Landolfi S, Helboe L, Schindler M, Cole SL and Bussolati G: Expression of somatostatin receptor types 1-5 in 81 cases of gastrointestinal and pancreatic endocrine tumors. A correlative immunohistochemical and reverse-transcriptase polymerase chain reaction analysis. Virchows Arch 440: 461-475, 2002.

37. van Adrichem RC, Kamp K, van Deurzen $\mathrm{CH}$, Biermann $\mathrm{K}$, Feelders RA, Franssen GJ, Kwekkeboom DJ, Hofland LJ and de Herder WW: Is there an additional value of using somatostatin receptor subtype $2 \mathrm{a}$ immunohistochemistry compared to somatostatin receptor scintigraphy uptake in predicting gastroenteropancreatic neuroendocrine tumor response? Neuroendocrinology 103: 560-566, 2016.

38. Okuwaki K, Kida M, Mikami T, Yamauchi H, Imaizumi H, Miyazawa S, Iwai T, Takezawa M, Saegusa M, Watanabe M, et al: Clinicopathologic characteristics of pancreatic neuroendocrine tumors and relation of somatostatin receptor type $2 \mathrm{~A}$ to outcomes. Cancer 119: 4094-4102, 2013.

39. Wang Y, Wang W, Jin K, Fang C, Lin Y, Xue L, Feng S, Zhou Z, Shao C, Chen M, et al: Somatostatin receptor expression indicates improved prognosis in gastroenteropancreatic neuroendocrine neoplasm, and octreotide long-acting release is effective and safe in Chinese patients with advanced gastroenteropancreatic neuroendocrine tumors. Oncol Lett 13: 1165-1174, 2017.

This work is licensed under a Creative Commons Attribution-NonCommercial-NoDerivatives 4.0 International (CC BY-NC-ND 4.0) License. 